\title{
Contribuições de Derek Walcott e Édouard Glissant para a narrativa histórica contemporânea desde o Caribe
}

\author{
Contributions by Derek Walcott and Édouard Glissant for contemporary \\ historical narrative from the Caribbean
}

Maria Angela Cappucci ${ }^{1}$

\begin{abstract}
Resumo
Dois dos mais importantes pensadores do século XX, o filósofo, romancista, poeta e dramaturgo Édouard Glissant (1928-2011), da Martinica, e o pintor, poeta, dramaturgo e ensaísta Derek Walcott (1930), da ilha de Santa Lucia, nas Antilhas, nos incitam a buscar em meio ao caos multicultural híbrido um novo estado-nação. Ao subverter os mitos do descobrimento da América, reinventaram imagens, paisagens poéticas e pictóricas em suas linguagens. É possível perceber um certo eco do neobarroquismo lezamiano da contraconquista, mas também um sinal de que o colonialismo tem novas formas de articulação na modernidade e que as pesquisas têm outras perspectivas de análise. Novas dimensões de espaço/tempo estão presentes nas narrativas literárias contemporâneas do Caribe como fontes para a história, inaugurando uma nova geopoética para o mundo.
\end{abstract}

Palavras-chave: antilhanidade; crioulização; poética do diverso.

\begin{abstract}
Two one of most important thinkers of twentieh century, the philosopher, poet and playwright Édouard Glissant (1928-2011) from Martinica, and the painter, poet, playwright and essayist Derek Walcott (1930), from Saint Lucian island, in the Antilles, instigate us to seek in the middle of the multicultural local hybrid caos a new nationstate. Subverting the myths of America discovering, they reinvented poetics and pictorials images in their languages. It's possible to feel the echoes of Lezama neo barroque achievement against, but also a signal that the colonialism has new adaptation forms in the modernity and the researches are new approaches of analisis. A new geopoetics and new space/time dimensions are present in contemporary literary narratives of Caribbean like sources to history.
\end{abstract}

Keywords: antillanity; creolization; poetics of the diverse.

Artigo recebido em: $31 / 08 / 2014$

Artigo aprovado para publicação em: 26/11/2014

\footnotetext{
${ }^{1}$ Doutora em História Cultural da América pela Universidade de Brasília. Este texto é parte da tese defendida em 2009 sob o título Imagens-mundo e história na literatura de Derek Walcott e da apresentação oral durante o X Colóquio Internacional Tradición y Modernidad en el Mundo Iberoamericano, realizado pela Universidade de Cádiz, Sevilha, entre os dias 2 e 5 de setembro de 2014. Email: macappucci@uol.com.br
}

\section{GANPHLAC}

Revista Eletrônica da ANPHLAC, ISSN 1679-1061, Nº. 17, p. 214-234, jul./dez. 2014. http://revista.anphlac.org.br/ 
Neste artigo, abordaremos algumas das contribuições das literaturas do Caribe à narrativa histórica contemporânea, muito semelhantes em suas imagens e linguagens, embora tenham sido escritas em idiomas diferentes.

As obras produzidas por esses dois pensadores antilhanos mencionados não estão dissociadas de suas biografias, e as narrativas sempre retornam ao lugar de origem, à natureza exuberante e tropical das Antilhas, com suas praias, sol, vegetação, clima, zoologia e aspectos geográficos, históricos, econômicos, sociais e culturais das populações locais. A ilha de Santa Lucia faz parte das Pequenas Antilhas, o arquipélago que, em continuação às Grandes Antilhas (Cuba, Jamaica, Hispaniola e Porto Rico), se estende das ilhas Virgens até a costa da Venezuela, tendo ao norte a ilha da Martinica, departamento francês de ultra-mar, e ao sul, Saint Vincent e as Granadines.

Derek Walcott é citado ao lado de Édouard Glissant como referência de "crioulidade", uma "política de mundialidade" pela qual os povos deverão se entender em sua mestiçagem cultural, numa relação nova, sem dominação cultural ou política do Outro. O passo inicial foi dado quando ambos, cada a um a seu modo, resolveram incorporar elementos da história oral regional (com tudo o que isso significa: incorporação de um novo tempo/espaço, novo sujeito, novas trocas simbólicas, língua creole, sons etc.) às línguas europeias "escritas" de origem colonial, o inglês e o francês. ${ }^{2}$ Walcott na pintura, na poesía épica, na dramaturgia, nos ensaios, e Glissant no romance, na poesia, na dramaturgia, mas também na sistematização de textos teóricos filosóficos, incorporaram a simbiose conhecida por "Oralitura". 3

Entre outros motivos, e não por coincidência, ambos disputaram o Prêmio Nobel de Literatura de 1992. Édouard Glissant perdeu o prêmio com uma de suas obras

\footnotetext{
${ }^{2}$ Creole - língua falada pelos descendentes de escravos que mescla a língua francesa com línguas africanas.

${ }^{3}$ A partir de 1954, Glissant começou a publicar artigos críticos na revista Les Lettres Nouvelles; desde essa época, sua produção como crítico cultural, romancista e poeta não se deteve jamais, conformando uma vasta obra. $O$ fato de ter nascido numa plantação (seu pai era chefe numa fazenda) fez-lhe conhecer a vida dura dos que trabalhavam na exploração da cana de açúcar, a única produção de recursos que vinha da época da escravidão, abolida em 1848. Conheceu também a realidade da colônia com sua herança de racismo, analfabetismo, pobreza, elementos que vão aparecer ao longo dos seus escritos. Durante a sua infância na plantação, Glissant esteve em contato com os contos que os contadores de histórias narravam toda noite às crianças. Espírito sensível, o futuro escritor recolhe os silêncios dessas histórias misturadas que se constituíram no lugar da memória oral, como uma das formas de resistência à opressão colonialista - cimarronagem que tem sido denominado como oralitura. Ver: ORTIZ, Graziela. $O$ mesmo e o diverso. (Comentários), 2001. Disponível em: http://www.ufrgs.br/cdrom/. Acesso em: 2004.
}

\section{GANPHLAC}

Revista Eletrônica da ANPHLAC, ISSN 1679-1061, No. 17, p. 214-234, jul./dez. 2014. http://revista.anphlac.org.br/ 
magistrais, o ensaio filosófico Poétique de la relation (1990), e Derek Walcott, ao recebê-lo, tornou-se mundialmente famoso com seu épico poético, e não menos grandioso, Omeros (1990). ${ }^{4}$

Quando o Prêmio Nobel chegou, esses autores já haviam escrito mais de três dezenas de obras, recebido vários prêmios e eram muito conhecidos tanto no Caribe quanto nos departamentos de literatura de língua francesa e inglesa, especialmente da França, EUA e Inglaterra, a exemplo de outros escritores que emigraram das ilhas na juventude para os países de lingua matriz.

Derek Walcott e Édouard Glissant, formam parte de um restrito grupo de autores aos quais se convencionou chamar de "migrantes" (RUSHDIE, 1990, 1991; BHABHA, 1998; GNISCI, 2004, 2005) que atravessaram as fronteiras geográficas, culturais e linguísticas de suas ilhas nas Antilhas, e, como um produto híbrido, enriqueceram suas identidades e perspectivas através de suas obras em plena era da globalização. ${ }^{5}$

Em Omeros, Walcott faz uma analogia entre a Odisseia de Homero e o cotidiano sofrido dos pescadores negros da ilha de Santa Lucia, onde nasceu. Grande parte da ação do livro não se desenrola na capital Castries, mas em Gros Îlet, situada na costa ocidental da ilha, perto de Pointe du Cap, o ponto extremo setentrional. É ali que vivem quase todos os protagonistas do poema. Uma pequena aldeia de pescadores, mas com ligações importantes com a história local. Em sua narrativa, coqueiros, praias, sol, aspectos geográficos e culturais do povo e do local formam o ambiente para uma nova versão do personagem Ulisses, agora no papel do pescador solitário, que sai para o mar

\footnotetext{
${ }^{4}$ Filho da professora de inglês Alix, Derek Alton Walcott cresceu com seu irmão gêmeo Roderick Alden e a irmã Pamela Avril, seis anos mais velha, sem conhecer o pai, Warwick, que faleceu aos 34 anos, quando os irmãos nasceram. Os pais eram grandes animadores culturais na ilha de Santa Lucia, mas, com a morte do pai, a mãe teve de costurar para manter a família. A memória do pai, funcionário público e pintor, o acompanhou por toda a vida. Fez sua primeira poesia aos 11, começou a pintar aos 12 e escreveu o primeiro livro de poemas aos 18 (25 poems). Na maior biografia já escrita sobre Walcott, King o descreve em sua contraditória ambiência mulata. $\mathrm{O}$ autor afirmou várias vezes sentir-se isolado, como mulato, desde a infância, tendo crescido entre duas etnias, a europeia e a negra, apesar de ser muito grato pela herança cultural recebida. A ambiência familiar da infância e adolescência reaparece em Another life (1972), no qual descreve o amor pela pintura, pelos pertences de seu pai, e a força de sua mãe. Quando Walcott nasceu, a população da ilha girava em torno de 80 mil habitantes, dos quais apenas $2 \%$ eram brancos e menos da metade falava inglês, apesar de o idioma ter-se tornado a língua da elite branca, dos educados de Castries - onde nasceu o autor e vivia mais de um terço da população negra e pobre. Ver KING, Bruce. Derek Walcott - a Caribbean life. New York: Oxford University Press, 2000.

${ }^{5} \mathrm{Em}$ nossa pesquisa de doutorado, entrelaçamos inicialmente as imagens pictóricas (pintura impressonista) e poéticas de Derek Walcott no período de 1990 a 2005. No pós-doutorado na Complutense de Madrid, em 2011, analisamos a recepção do mito (grego clássico e outros) nas obras de Derek Walcott, Édouard Glissant e Jose Lezama Lima.
}

\section{GANPHLAC}

Revista Eletrônica da ANPHLAC, ISSN 1679-1061, No. 17, p. 214-234, jul./dez. 2014. http://revista.anphlac.org.br/ 
em aventuras diárias, em busca da subsistência num meio hostil. No livro aparecem, em forma de poesia, todos os elementos da vida do autor, bem como as fontes de inspiração que o levaram a escrever a obra, segundo Vizioli (1994, p. 5-28):

\begin{abstract}
Assim, no segundo capítulo está descrito o dia em que, no atelier de uma jovem grega, ao ver um busto de Homero, Walcott teve a inspiração em Boston para a realização do livro; no capítulo XII estão suas recordações da infância e da figura paterna; no capítulo XXII, as lembranças da mãe, todas associadas ao lugar atravessado pelo rio Castries, o mercado, a cidade, o porto, a igreja católica. No capítulo LVI, a figura de Omeros, o poeta cego que observa e interpreta os fatos, tem seu representante na ilha de Santa Lúcia na pessoa de um preto velho, também cego, que, depois de passar a maior parte da vida navegando pelo mundo, identifica-se com o mar e, por meio dele, com seu antecessor grego, cujo significado para o autor - é essencialmente "júbilo/júbilo na batalha, no trabalho, na morte - e a paz enumerada/das bençãos da rebentação". Sentado com seu cão à sombra da farmácia (lugar de "cura" da aldeia Gros Îlet), Sete Mares conhece os males da humanidade e prevê o seu destino; é o bardo e o profeta, igualando-se ao griot dos africanos e ao xamã dos indígenas, duas outras manifestações de Omeros igualmente presentes no poema.
\end{abstract}

Autores que o influenciaram também aparecem implícitos no livro, como James Joyce e Dante, deixando marcas tanto na estrutura geral da obra quanto em cenas individuais - embora Omeros se distinga de Ulysses por abranger também a Ilíada e pelo caráter eminentemente épico em vez de satírico (VIZIOLI,1994, p. 5-28).

Como mulato, nunca pode ser aceito integralmente pela sociedade branca anglosaxônica da Inglaterra e dos Estados Unidos; por outro lado, nem sempre tem sido compreendido pela comunidade negra, devido a posturas moderadas frente ao problema racial. Como descendente de africanos, busca, a exemplo de outros autores caribenhos, reencontrar sua identidade nos costumes oriundos do Golfo da Guiné, até mesmo nas tradições tribais de seus antepassados negros; como descendente de brancos, não deseja desligar-se da herança cultural deixada pelos colonizadores de Santa Lucia. E não faz questão de ocultar influências de autores ingleses como T. S. Eliot, W. H. Auden, Dylan Thomas, William Butler Yeats, William Shakespeare, John Donne e Andrew Marvell, ou de romancistas como James Joyce, Rudyard Kipling, Joseph Conrad e Ernest Hemingway, influentes em sua formação.

A complexidade de sua herança cultural reflete-se em seus poemas afiados, que misturam o inglês, o latim, o francês e o creole. Em seu texto eloquente há uma hábil mistura de folclore e tradição oral, de clássico e moderno nas colocações sobre a história, a paisagem, a vida cotidiana e a multirracialidade das ilhas. Ele também se

\title{
GANPHLAC
}

Revista Eletrônica da ANPHLAC, ISSN 1679-1061, No. 17, p. 214-234, jul./dez. 2014. http://revista.anphlac.org.br/ 
interroga sobre sua herança europeia e africana, referindo-se a conflitos pessoais, muitos dos quais emergem de suas inquietações. ${ }^{6}$

De acordo com Vizioli (1994, p. 5-28),

Os versos de Omeros são hexâmetros, bastante flexíveis, em que os pés jámbicos (yambic pentameters), trocaidos e outros se alternam livremente. Nem mesmo a manutenção dos seis acentos fortes em cada linha é observada com rigor, havendo alguns com cinco ou menos. As estrofes são tercetos lembrando a disposição gráfica das páginas da Divina Comédia, sem dúvida numa homenagem a Dante.

Um exemplo da mescla de elementos regionais e línguas em Omeros pode ser vista na abertura do capítulo III:

"Touchez-i, encoré: N'ai fendre choux-ous-ou, salope!"

"Mexa nisso de novo, e eu lhe parto a bunda, seu filho da puta!"

"Moi j'a dire -- 'ou pas prêter un rien: 'Ous ni shallope,

'ous ni seine,' ous croire 'ous ni choeur campêche?"

"Eu já lhe disse, não pegue nada que é meu. Você tem sua canoa

e sua rede. Quem você pensa que é? O miolo do pau-campeche?"

“' 'Ous croire 'ous c'est roi Gros Ilet? Voleur bomme!"

"Você acha que é o rei de Gros Îlet, seu ladrão de lata?"

Depois em inglês: "I go show you who is king! Come! Eu lhe mostro o rei! [Venha!"

Hector saiu da sombra. E Achille, no instante em que o viu trazendo o facão, un homme fou, um louco

roído de inveja, recolocou com um gesto nítido

a lata, que emprestara da canoa de Hector, na proa

do barco de Hector. Então Achille, que já estava cansado

desse louco, limpou e ergueu sua própria lâmina.

E agora os moradores da vila emergiram da sombra verde das amendoeiras e mancenilheiras de folhas de cera, para o confronto que Hector desejava. Achille se afastou e esperou

na borda quente dos baixios. Hector avançou em sua direção.

O povo da aldeia o seguiu, enquanto a rebentação abafava

O seu som, seu medo a encolher-se ante a beira da praia.

\footnotetext{
${ }^{6}$ A obra de Derek Walcott surpreendeu sociolinguistas e poetas como o escritor russo Joseph Brodski, que o despojou de todos os ismos: [...] "pois ele pode ser naturalista, expressionista, surrealista, imagista, hermético, confessional... escolha o que quiser. Ele simplesmente absorveu, de modo como as baleias absorvem o plâncton ou o pincel as cores da paleta, todas as expressões estilísticas que o norte podia oferecer; agora tornou-se ele mesmo, e com grandeza". (VIZIOLI, 1994, p. 5-28)
}

\section{GANPHLAC}

Revista Eletrônica da ANPHLAC, ISSN 1679-1061, No. 17, p. 214-234, jul./dez. 2014. http://revista.anphlac.org.br/ 
Então, bem longe ao largo, numa chuva cintilante, Flechas de chuva voaram em arco do esmeraldino quebra-mar do arrecife, os dardos viajando com claro poder

ao sol, e atrás deles, alinhados para a matança, postaram-se os aldeões, gritando, com um som igual ao do baixio, e alçando braços à luz. Hector correu, chapinhando

no raso em meio ao chuvisco, para onde estava Achille, no alto o facão. A rebentação, com raiva, a morder a própria cauda, como espumejante briga de cães. Homens em fúria

podem matar seus próprios irmãos, mas o louco que rasgou a camiseta de Achille de um ombro também rasgou seu coração. A fúria que ele sentía contra Hector

era vergonha. Endoidecer por causa de uma lata velha de achicar, coberta de ferrugem! Esses pescadores duelavam por uma sombra, e seu nome era Helen. ${ }^{7}$ (WALCOTT, 1994, p. 41)

O caráter metafórmico de personagens, cenas e situações é vasto. Além de representar a natureza, Helen, a deslumbrante criada negra de olhos amendoados de Omeros, é uma referência à bela Helena, pomo da discórdia entre gregos e troianos, e forma um trio amoroso com os pescadores Achille e Hector. Mas, em momentos diversos, pode encarnar rapidamente a dominadora Calipso, a jovem Nausícaa, ou Circe, a feiticeira que transforma os homens em porcos, e pelo menos uma vez se identifica com Penélope. Vejamos um trecho do cap. VII:

As bancas do mercado continham tanto a história das Antilhas quanto a de Roma, os frutos de um mal, onde os pratos-de-metal oscilantes só se equilibravam

com a lágrima férrea do peso - cada bacia de latão nivelada no mesmo horizonte - mas nunca iguais, como o velho e o novo mundo, com a equidade das aparências.

Saíram do mercado-de-ferro. Achille devolveu a Helen a cesta cheia. Disse Helen: "Ba moin!" "Você dá ela pra mim?!"

Achille respondeu: "Olhe! Não sou seu

[escravo!

\footnotetext{
${ }^{7}$ Tradução de Paulo Vizioli, da edição brasileira de Omeros, de Derek Walcott, pela Companhia das Letras, 1994.
}

\section{GANPHLAC}

Revista Eletrônica da ANPHLAC, ISSN 1679-1061, No. 17, p. 214-234, jul./dez. 2014. http://revista.anphlac.org.br/ 
Você tem que se mostrar a tal para os outros?". Naturalmente, ela riu com aquela risada alta e sonora, e foi andando na frente dele. E ele, sentindo-se como um cão que é deixado (WALCOTT, 1994, p. 60) ${ }^{8}$

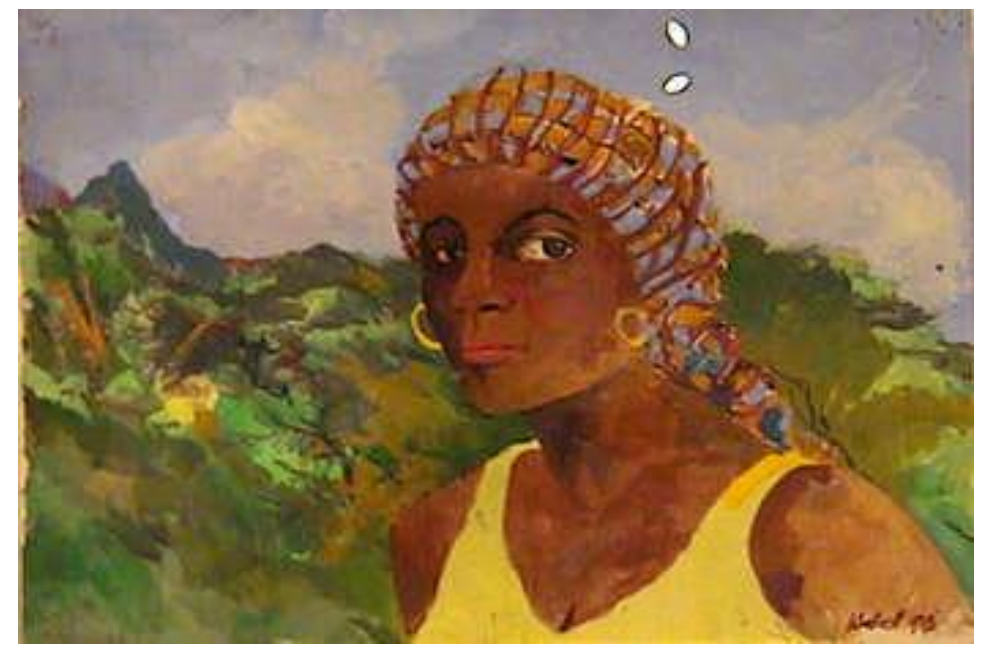

Figura 1 - Helen Ideal Head: Helen/Omeros, 1998, Guache e aquarela.

Os personagens odisseicos aparecem desde as primeiras obras de Derek Walcott e Édouard Glissant, mas há diferenças, ainda que, em síntese, os personagens encarnem os escravos e seus descendentes.

No caso de Walcott, os heróis (descendentes de escravos ou a própria figura do narrador/persona) se metamorfoseiam em vários. Eles podem ser representados por um marinheiro, um náufrago, um viajante, um vagabundo, um pescador, mas jamais são exilados - Derek Walcott prefere a figura do viajante à do exilado. Em alguns poemas, como em Tiepolo's Hound (2000) - no qual presta uma homenagem ao pintor impresionista Camille Pissarro, o viajante/persona, ou narrador, se confunde com a própria figura do autor. O poema é sofisticado, e tanto o personagem principal quanto o narrador/persona circulam por vários lugares do mundo.

\footnotetext{
8“"Em Omeros, Derek Walcott, ao não se restringir ao universo da Odisséia, mas abranger também a Ilíada, reproduziu os embates entre Aquiles e Heitor. Isso permitiu ao autor desenvolver paralelamente o tema do entrechoque dos impérios, analisando assim a natureza do imperialismo, a principal causa da falta de raízes das raças oprimidas. Esse entrechoque se apresenta no Caribe através da rivalidade entre ingleses e franceses pela posse das Pequenas Antilhas - entre elas Santa Lucia. É a eterna briga por Helena, símbolo agora dos encantos da natureza e das riquezas que a ilha encerra. Mas o tema se robustece com alusões a muitos outros entrechoques e impérios ao longo da história, como Grécia e Roma, Portugal e Espanha - que, com o Tratado de Tordesilhas, chegaram a dividir o mundo entre si (cap. XXXVII) --, Istambul e Veneza (cap. XL, iii), e outros mais, culminando com a guerra fria entre os Estados Unidos e a União Soviética." (VIZIOLI, 1994, p. 5-28).
}

\section{GANPHLAC}

Revista Eletrônica da ANPHLAC, ISSN 1679-1061, No. 17, p. 214-234, jul./dez. 2014. http://revista.anphlac.org.br/ 


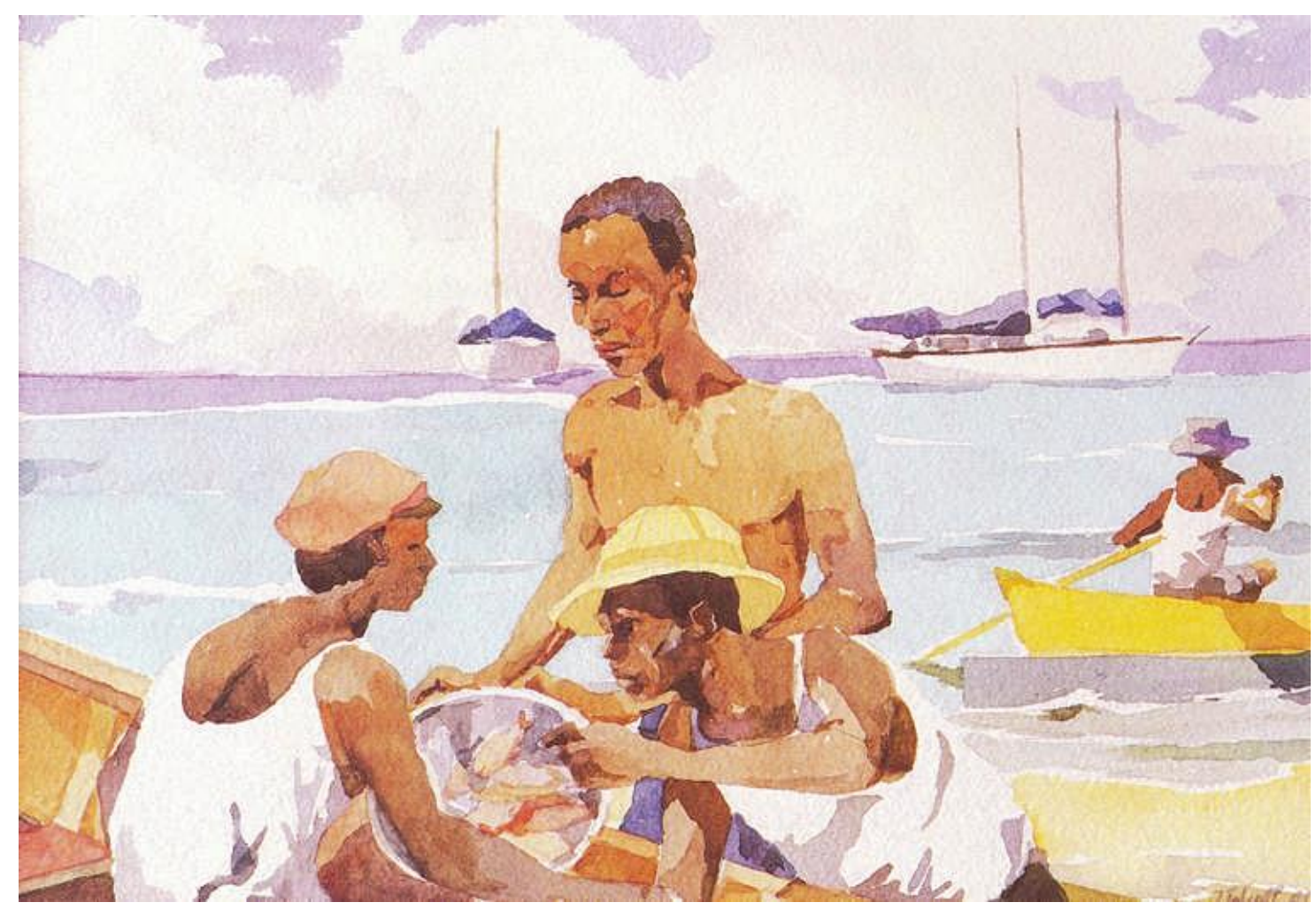

Figura 2 - St. Lucian Fishermen, 1991/ Aquarela, 7 “x 1/4”.

O herói de Glissant é o escravo negro que chegou ao Caribe totalmente despossuído, aviltado como exilado, navegante errante, levando consigo, dentro do navio negreiro, apenas a sua memória ancestral toda fragmentada. Ele pode continuar sendo um marron (escravo fugido) ou algum personagem adaptado à realidade da ilha nas comunidades em torno das plantations.

\section{Long Durée}

O passado e o presente se confundem nas obras desses dois escritores. A poética do tempo e a ocultação da história de um povo por outro pode ser vista no romance $L e$ quatrième siècle (1962), de E. Glissant, que funciona como uma máquina do tempo caótico, fragmentado. "Máquina paradoxal que tem por objeto oferecer uma visão profética do passado como se fosse o futuro, e vice-versa, num movimento em espiral que pode conjugar tempos diferentes" (CHEVRIER, 1998, p. 8-10).

\section{GANPHLAC}

Revista Eletrônica da ANPHLAC, ISSN 1679-1061, Nº. 17, p. 214-234, jul./dez. 2014. http://revista.anphlac.org.br/ 
O romance é comparável a outro de Alejo Carpentier, El siglo de las luces (1962), no qual o herói tem por objeto uma concha em forma de espiral, um búzio, no qual ele vê o símbolo mesmo de "todos os barrocos que virão". O búzio é o mediador entre o que esvanece e as estruturas e alternâncias do imponderável.

Em Le quatrième siècle, Glissant se recusa a construir um romance baseado na dialética entre senhor e escravo. O que está em jogo é a relação complexa e muitas vezes antagônica entre o escravo e o marrom (o negro fugido). Estes são incorporados na história de duas famílias paralelas e mistas, os Béluse e os Longoué, num longo período desde 1788 , data da chegada às ilhas do primeiro ancestral de cada linha, até 1946 - data em que pontuam elementos do romance La Lézarde, 1958 (JOUBERT, 2005, p. 1-75).

À chegada, os Longoué rejeitaram a escravidão e "marronaram" (marronage) nas colinas por encontrar a liberdade nos mornes. Os Béluse permaneceram nas plantações da família creole de Senglis e suportaram a escravidão. Para Glissant, "existe em todas as Antilhas um Longoué e um Béluse, um ser que recusa e um ser que aceita":

O romance vai contra a facilidade do afresco histórico: e revela a história encoberta, reprimida, desviando o caminho para a libertação, soltando os cavalos de uma língua habitada e violenta, obscura e poética, tendendo para a energía da oralidade subjacente. (JOUBERT, 2005, p. 1-75)

O romance é organizado com base nas histórias que Papa Longoué, o último descendente de sua linhagem, um velho quimboiseur (detentor de um conhecimento legado pela tradição) conta ao jovem e letrado Mathieu Béluse, que se impacienta em agir contra a sorte de seus pais e aceitar humildemente seu destino. Diz Mathieu ao quimboiseur: "Mais tu va trop vite! Est-ce que tu ne peux pas proclamer les dates l'une après l'autre-et finir de tourner, en avant, en arrière? Tu tourbillonnes commes la poussière de Fonds-Brûlé.” (CHEVRIER, 1998; JOUBERT, 2005, p. 1-75)

Esse turbilhonamento da/na linguagem ou "irruê" - expressão decorrente do som saído de um vulcão, lembrando a natureza violenta e em constante mutação do Caribe -, foi incorporada na linguagem de Glissant, além dos ritmos musicais locais, como a música cantada nas plantations (GLISSANT, 2002).

\section{GANPHLAC}

Revista Eletrônica da ANPHLAC, ISSN 1679-1061, No. 17, p. 214-234, jul./dez. 2014. http://revista.anphlac.org.br/ 
"Nossas histórias são respirações longas sem principio nem fim, onde os tempos se envolvem", diz Glissant numa referência à metáfora espiral. As últimas páginas do romance fazem uma síntese de reconciliação entre a continuidade da revolta dos Longoué e o ramo laborioso e fecundo dos Béluse.

Segundo Joubert, Glissant titula de romances poemas ou coleção de ensaios, textos com fronteiras permeáveis. Dessa forma, o romance La Lézarde, por exemplo, foi escrito como um poema dentro do romance; alguns capítulos de Tout monde (1993) são abertos com citações contidas em Traité du tout-monde (1997), obra que, por sua vez, contém uma seção intitulada "Le Traité du Tout Monde de Mathieu Béluse", personagem que aparece com perfis diferentes nos romances La Lézarde e Mahagony (1987). ${ }^{9}$

Glissant elaborou uma série de idéias reconstruindo fragmentos do passado de povos que foram espoliados, a seu ver. Várias obras, entre elas Le discours antillais (1981), Poétique de la relation (1990), Poétique du divers (1995) e Traité de toutmonde (1997), vão introduzindo reflexões sobre o literário, o histórico e o cultural que ultrapassam o espaço geográfico das Antilhas e o tornam importante.

Naquelas obras, durante décadas, retrabalhou conceitos como os de antilhanidade (antillanité), noção de identidade a partir das análises das realidades existentes e compartilhadas pelas culturas caribenhas; e o de crioulização (créolisation), conceito central da "poética da relação" que postula uma maneira de frequentar o mundo na diversidade, a partir da ideia de identidade-rizoma, inspirada nos filósofos franceses Deleuze e Guattari. A ideia do "respeito ao Diverso" (as diferenças consentidas) é contrapor à raíz única, que mata tudo em volta, o rizoma que se caracteriza por ser uma raíz múltipla a estender-se numa relação com o Outro sem prejudicar as outras.

Esse respeito não se impõe pela força, mas por uma mudança dos imaginários, pela aceitação da ideia de que temos necessidade de todas as comunidades e todos os imaginários para poder viver. "A poética da relação" é tecida no encontro dinâmico de todas as histórias particulares misturadas, é uma maneira de frequentar essa totalidade-

\footnotetext{
${ }^{9}$ Mathieu é o nome dado a vários personagens nos livros de Édouard Gissant, emprestado de seu filho mais novo, Mathieu Glissant.
}

\section{GANPHLAC}

Revista Eletrônica da ANPHLAC, ISSN 1679-1061, No. 17, p. 214-234, jul./dez. 2014. http://revista.anphlac.org.br/ 
mundo que não deve ser pensada como um absoluto, mas como um movimento que se refaz constantemente e que, por sua força poética, tende a se aperfeiçoar.

A força da memória que Glissant resgata no grito do escravo que é levado no navio negreiro até as Antilhas e, depois, nas plantations, foge para a montanha (marronage), é o elemento primordial que sustenta sua defesa na inserção da cultura negra antilhana oralizada no contexto mundial. "Está na hora do escrito voltar-se para o oral", afirma Glissant (2002).

O grito ecoado do navio e empurrado para dentro dos mornes (picos existentes na Martinica) pelos primeiros quilombolas (marrons ou escravos fugidos) produziu a linguagem. Linguagem que tem sua gênese comparada, da mesma forma, às epopeias clássicas e aos textos fundadores dos nativos americanos, como o Popol Vuh, por exemplo, perpetuando a identidade da comunidade dentro da filiação por gerações. Contudo, Glissant propõe um outro modo épico que é "a canção redentora da derrota ou da vitória ambígua" (JOUBERT, 2005, p. 1-75).

A única coisa escrita encontrada dentro dos navios negreiros, segundo Glissant, foi a relação dos preços dos escravos que seriam comercializados. Dentro do espaço do navio negreiro, no entanto, o choro dos escravos foi sufocado, assim como nas plantations, produzindo uma confrontação que reverbera até hoje. Ao chegar ao Caribe, eles eram separados de diversas maneiras, entre as quais, pelos idiomas falados na África. Em mais de dois séculos, 30 milhões de pessoas foram deportadas (GLISSANT, 1990, p. 17-20).

[...] Essa situação absurda, no entanto, não os impediu de criarem um povo único, criativo, articulado em sua diversidade cultural e aberto ao mundo. As linguas africanas desterritorializadas foram compensadas pela memória trazida nos barcos e desenvolvida nas plantations. [...] Nascia assim, para Glissant, uma Relação não de estrangeiridade, mas de conhecimento compartilhado. No livro Poétique de la Relation (1990) o ventre do barco está aberto e Glissant reafirma que o grito nascido das Antilhas não foi em vão, pois nossos barcos, navegaram por todos chamando a atenção do Ocidente para os exemplos que vêm do Caribe de uma relação baseada na diversidade ou na poética do Diverso (Créolisation).

\section{GANPHLAC}

Revista Eletrônica da ANPHLAC, ISSN 1679-1061, Nº. 17, p. 214-234, jul./dez. 2014. http://revista.anphlac.org.br/ 
Comparado por Glissant a um útero que navegava sobre o abismo marinho, esse barco, apesar das inúmeras mortes decorrentes dos maus-tratos e enfermidades, acabou produzindo um "pensamento de rastro", contribuindo com a creolização do Oeste: "a maior confrontação entre o poder da palabra escrita e os impulsos da oralidade" (GLISSANT, 2002). ${ }^{10}$

São muitos os conceitos e ideias desenvolvidos por Glissant ao longo de décadas, contidos nas obras, em torno de alguns padrões ou palabras que aparecem desde seus primeiros textos: relacionamento (Relation); vários (Divers); opacidade (opacité); miscigenação (métissage); além de antilhanidade (antillanité); e crioulização (Créolisation). Diverso por exemplo, é uma palavra emprestada de Victor Segalen e significa "o esforço do espírito humano para uma relação transversal, sem transcendência universalista" (JOUBERT, 2005, p. 1-75).

A ideia do L'Un (o Um), do qual Même declina, instalou e impôs ao mundo sua identidade (vários sentidos da palabra). O princípio da transcendência universalista. Le Même et les Divers (o Mesmo e o Diverso) são retomados dentro de Les discours antillais (1981), ou ele é apresentado como a manifestação de uma grande mudança na ordem da civilização, acompanhando o fim da colonização..

A reflexão sobre o $L$ 'Un e o Divers, inicialmente ancorada na análise da situação antilhana e da realidade colonial, em seguida, foi estendida a um pensamento do Tout-Monde, que nos textos mais recentes, é definido como o caos-mundo (o termo é forjado a partir dos trabalhos sobre psique e caos), não é nem fusão ou confusão, nem amálgama, nem uniformização, nem nada informa. Ele é o Diverso infinito numa obra em que o choque, o emaranhado, as repulsões, as atrações, as convivências, as oposições, os conflitos entre as culturas dos povos se dão na diversidade contemporânea. O turbilhão do mundo, o entrelaçamento de culturas leva a resultados para além da previsão. Graças a essa desconstrução-recomposição do caos-mundo, o Diverso se inventa perpetuamente (JOUBERT, 2005, p. 1-75).

${ }^{10} \mathrm{O}$ tráfico negreiro sugere a Glissant uma comparação entre as epopeias clássicas ocidentais, como a Ilíada e a Odisséia, e as africanas, que foram consideradas "singelamente" por Hegel "conscience naïve" do momento popular do épico, obviamente contestada por Glissant.

\section{GANPHLAC}

Revista Eletrônica da ANPHLAC, ISSN 1679-1061, Nº. 17, p. 214-234, jul./dez. 2014. http://revista.anphlac.org.br/ 


\section{Paisagem Caribenha}

Derek Walcott e É. Glissant também falam do conceito de paisagem aplicado como modelo de humanidade, conforme ideias extraídas de Ernst Robert Curtius, e seu livro Literatura europea y Edad Media latina (1949), no qual o autor observa que todos os parâmetros da literatura europeia têm um tópico que é a paisagem ideal: a do prado e a da fonte. "Me dei conta que, no caso Caribe é diferente porque todas as literaturas falam da selva, dos terremotos e das tormentas". Para Glissant,

[...] En nuestras literaturas, el paisaje no es un decorado, sino un personaje en si mismo. Tenemos dos variantes de paisaje. Primero, porque vinimos por mar, a través del Paseo del Medio hacia las islas, y allí imaginamos el mar. Y, junto con esto, estábamos en el periodo de la esclavitud. Al decir esclavitud pienso en los cimarrones que huyeron hacia el bosque, hacia las montañas, para liberarse. Portanto, nuestras ideas de libertad están vinculadas a las montañas y al mar. Y la libertad debemos conseguirla entre ambos extremos, entre las montañas y el mar. (PHAF-RHEINBERGER, 2008, p. 311-329)

Em Introducción a una poética de lo diverso (2002, p. 16-17), Glissant retoma sua teoria que distingue o mar Mediterrâneo do mar do Caribe na justificativa da ideia do L'Un (o Um). A diferença, segundo ele, é que o primeiro é um mar que "concentra", enquanto o segundo "difracta".

El hecho de que las civilizaciones y las grandes religiones monoteístas surgieran en las proximidades de la cuenca mediterránea obedece al poder de este mar para dirigir, incluso por medio de los dramas, las guerras y los conflitos, el pensamiento humano hacia un pensamiento de lo Uno y de la unidad. El mar Caribe, por su parte, es un mar que difracta y que suscita la emoción de la diversidad. No es únicamente un mar de tránsito y travesías, es también un mar de encuentros y de implicaciones. Lo que sucede en el Caribe en tres siglos es literalmente esto a saber: la coincidencia de elementos culturales provenientes de horizontes absolutamente diversos y que realmente se criollizam, realmente se imbrican y se confundem entre si para alumbrar algo absolutamente imprevisible, absolutamente novedoso, que no es otra cosa que la realidade criolla. (GLISSANT, 2002, p. 1617)

\section{GANPHLAC}

Revista Eletrônica da ANPHLAC, ISSN 1679-1061, No. 17, p. 214-234, jul./dez. 2014. http://revista.anphlac.org.br/ 


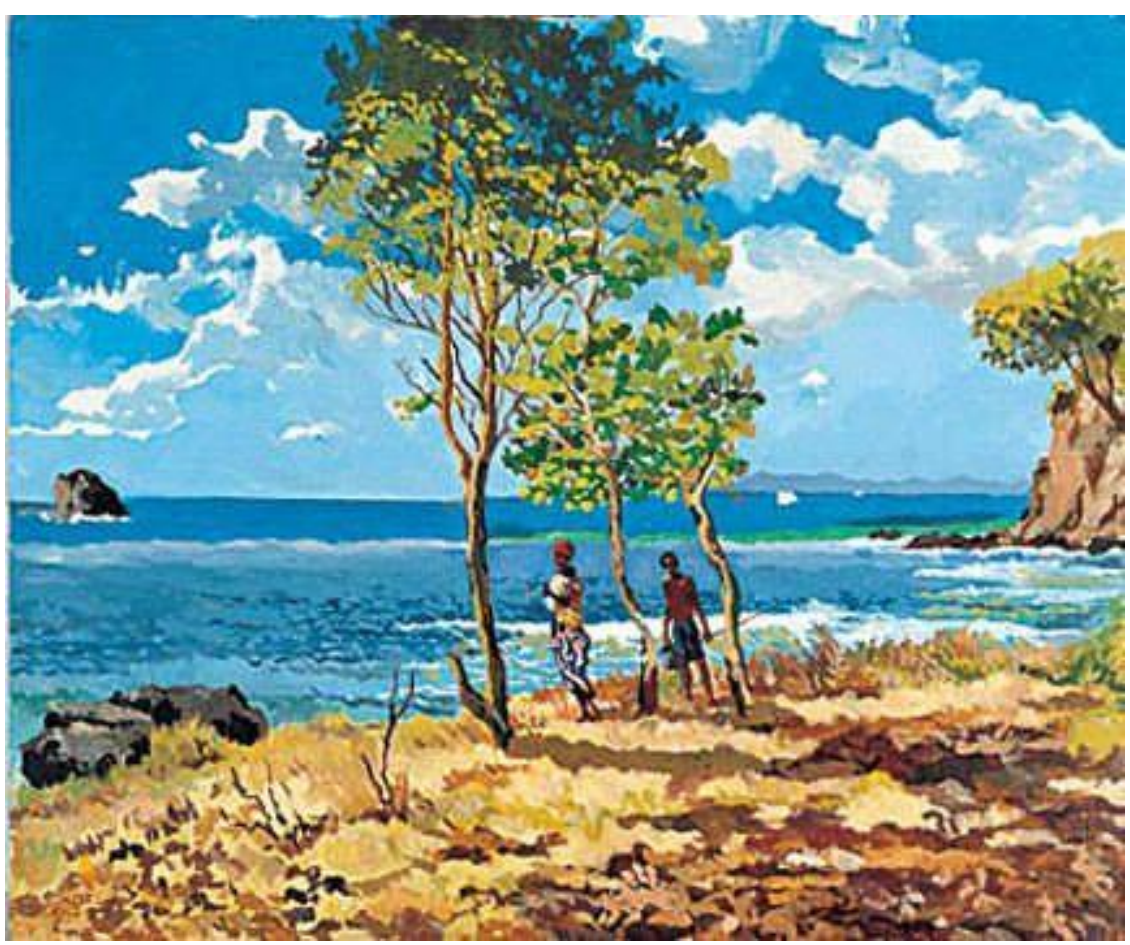

Figura 3 - Seascapes with Figures, 2002/Óleo sobre madeira, 20 "x 24".

Essa nova geopoética a partir do Caribe para o mundo pode ser verificada inclusive nas pinturas e na dramaturgia de Derek Walcott, entre outros autores caribenhos. Em busca de uma nova gênese do povo caribenho, e de uma nova epopeia fundacional, Glissant e Walcott defendem a lingua/cultura creole e a paisagem caribenha como parte da criação de uma linguagem-nação. De acordo com o escritor jamaicano Kamau Brathwaite, a linguagem-nação não é ensinada nas escolas, nasceu da convivência nas plantations, nas canções populares, mas também expressa a experiência de um povo oprimido que tem sido criticado e denegrido pelo establishment, devido a seu status. Ao contrário do dialeto, ela implica um "cosmos-língua" por direito próprio (PHAF-RHEINBERGER, 2008, p. 311-329).

Educado em escolas de língua inglesa como Derek Walcott, Brathwaite fala da dificuldade em traduzir em versos conhecidos como yambic pentameters (pentámetros yámbicos), tão comuns na liteturatura de Milton e Shakespeare, a gênese de um povo. "Seria impossível, segundo ele, se não fosse a linguagem-nação criar, por exemplo, um

\section{GANPHLAC}

Revista Eletrônica da ANPHLAC, ISSN 1679-1061, Nº. 17, p. 214-234, jul./dez. 2014.

http://revista.anphlac.org.br/ 
poema que mesclasse os sons do steelpan, do calypso de Trinidad a um antigo conto afro caribeño da anasni". ${ }^{11}$

Numa pesquisa sobre a história da poesía inglesa no Caribe, Baugh (2001, p. 252254) repara na evolução permanente de Derek Walcott, sempre em busca de novos caminhos até mesmo para os versos yambic pentameters da poesia inglesa. Em Omeros, "moderniza a terza rima, uma das formas europeias que mais o atraiu". Ao longo dessa odisseia das formas do verso, e em alguns casos complicando a característica de seu próprio estilo, Walcott prende o uso da imagem à metáfora. Com todos esses tropos, "Walcott reinventou a paisagem caribenha; o poeta se define pela paisagem e o povo que a habita”. Na história de dor, herdada pelo povo do Caribe, há um instante que o poeta pode resumir com uma simples palavra. A ideia da tirania da História tornou-se o tema central.

Tanto Walcott quanto Glissant trazem à tona o chamado "sujeito metafórico", em meio à paisagem caribenha e ao caos, uma ideia que aparece com força no livro Expressão americana (1957), do escritor cubano Jose Lezama Lima.

Segundo Hirsch (1998),

a tarefa para o artista antilhano híbrido é fundir os diversos fragmentos, pegar os pedaços africanos, asiáticos, europeus e formar um novo todo que se goza no fermento e na babel, glorificando a marchetaria das Îndias Ocidentais. ${ }^{12}$

Essa descrição de Hirsch aproxima Derek Walcott e Glissant das concepções do cubano, sobre o estilo do artista neobarroco latinoamericano do século XX, cuja “diversidade cultural, longe de ser um embaraço, transformou-se na própria fonte de

\footnotetext{
${ }^{11}$ Segundo Kamau Brathwaite: steelpan - "es literalmente un 'tambor de acero', o 'tambor metálico”, es un instrumento de percusión musical y designa, por extensión, el género musical al que éste da lugar. Preservo la expresión en inglés pues su uso se há extendido en el idioma castellano; Anansi, en los cuentos criollos caribeños es la araña, muchas veces mezclada con humano, y simboliza la astucia popular. El vocablo es originário del África ocidental selvática. Otro gran personaje de los cuentos africanos, esta vez en zona de sabana, es la liebre, la que tanbién tiene presencia criolla." (PHAFRHEINBERGER, 2008, p. 311-329).

${ }^{12}$ Edward Hirsch, poeta e ex-colega de Derek Walcott na Universidade de Albany, EUA, refere-se ao texto de Derek Walcott, The Muse of History (1974), reeditado em outras publicações também em castelhano disponível em www.fractal.com.mx/f14walcol.html. Acesso em: 2004.
}

\section{GANPHLAC}

Revista Eletrônica da ANPHLAC, ISSN 1679-1061, Nº. 17, p. 214-234, jul./dez. 2014. http://revista.anphlac.org.br/ 
criatividade, na arte da contraconquista, proposta anteriormente por José Martí" (CAMPOS, 2003).

No livro, Lezama assinala que, enquanto o barroco europeu se caracteriza por sua "acumulação de tensão", o barroco iberoamericano significa o oposto. O traço diferenciador entre a estética barroca do século XVII e o neobarroco se encontra na riqueza da natureza da América. "O barroco é uma arte autóctone da América que tem suas raízes na graça de seu espaço e na mestiçagem de seus habitantes”.

Ao imaginar uma nova Renascença em cores barroco-tropicais, Derek Walcott e Édouard Glissant fizeram da linguagem, centrada no logos poético e na fábula intertextual, ferramentas importantes na subversão das narrativas tradicionais do Descobrimento da América, em 1492, comparando o tráfico negreiro e a diáspora africana à expulsão dos judeus da Espanha. Mas também tentaram inserir a diferença cultural das populações negras e pobres do Caribe, no polêmico e globalizado terreno da chamada Literatura Mundial. ${ }^{13}$

Ao desconstruir o chamado "código renascentista" que inspirou o expansionismo europeu anglo-saxônico - cristão no continente sul-americano, levando consigo os valores da cultura greco-romana, esses autores passaram a imaginar um novo mundo começando pelas contribuições culturais dadas a partir do amálgama de povos africanos que criaram a lingua creole e um pensamento baseado na diversidade, desde as plantations para o mundo, numa nova geopoética. ${ }^{14}$

\footnotetext{
${ }^{13}$ A expressão literatura mundial foi cunhada por Goethe em uma das conversas mantidas com Eckerman em 31 de janeiro de 1827, após o autor revelar estar maravilhado com a literatura chinesa, antevendo a língua alemã como a melhor para traduzi-la ao Ocidente. Desde então, tudo o que é mundial (e nacional) passou a ser também universal, estabelecendo a hegemonia da língua alemã sobre as outras literaturas. A discussão a partir daquele momento vem permeando os congressos de literatura comparada nas línguas inglesa e francesa, todos tentando justificar igualmente a hegemonia de suas línguas sobre outras literaturas. Ver ECKERMANN, J. P. Conversaciones con Goethe: en los últimos años de su vida. Edición y traducción de Rosa Sala. Barcelona: Acantilado, 2005, 1003 p. e CASANOVA, Pascale. A literatura como mundo Grial, Revista Galega de Cultura. Vigo: Galáxia/Fundación Caixa Galicia, n. 167, p. 13-25, julho a setembro 2005 .

${ }^{14}$ Geopoética - termo criado pelo escocês Kenneth White (1978) para o movimento em defesa do planeta Terra, que pretende unir poetas e pensadores na construção de uma nova cartografia mundial baseada numa rede de interesses comuns que respeite os reinos mineral, animal, vegetal em sua biodiversidade e igualdade com os humanos. Os intelectuais nômades de referência são Friedrich Nietzsche, Arthur Rimbaud, Henry Thoreau (ornitógolo e meteorologista) e Patrick Geddes, além do poeta caribenho John Perse. Mas é possível perceber também a proximidade das ideias de Édouard Glissant nesse contexto.
}

\section{GANPHLAC}

Revista Eletrônica da ANPHLAC, ISSN 1679-1061, No. 17, p. 214-234, jul./dez. 2014. http://revista.anphlac.org.br/ 
Uma das dificuldades em captarmos toda a beleza poética e ao mesmo tempo a utopia constante na obra de Derek Walcott e Édouard Glissant na idealização de uma sociedade caribenha baseada na música e no respeito à diversidade multicultural está na fragmentação das obras e personagens, nos variados tempos/espaços da nova literatura migrante, decorrentes da própria história do Caribe, marcada por sucessivas invasões coloniais, narrativas construídas a partir da criação do "novo mundo", dos deslocamentos populacionais e diásporas e não mais por binarismos do tipo colonizador/colonizado, senhor/servo.

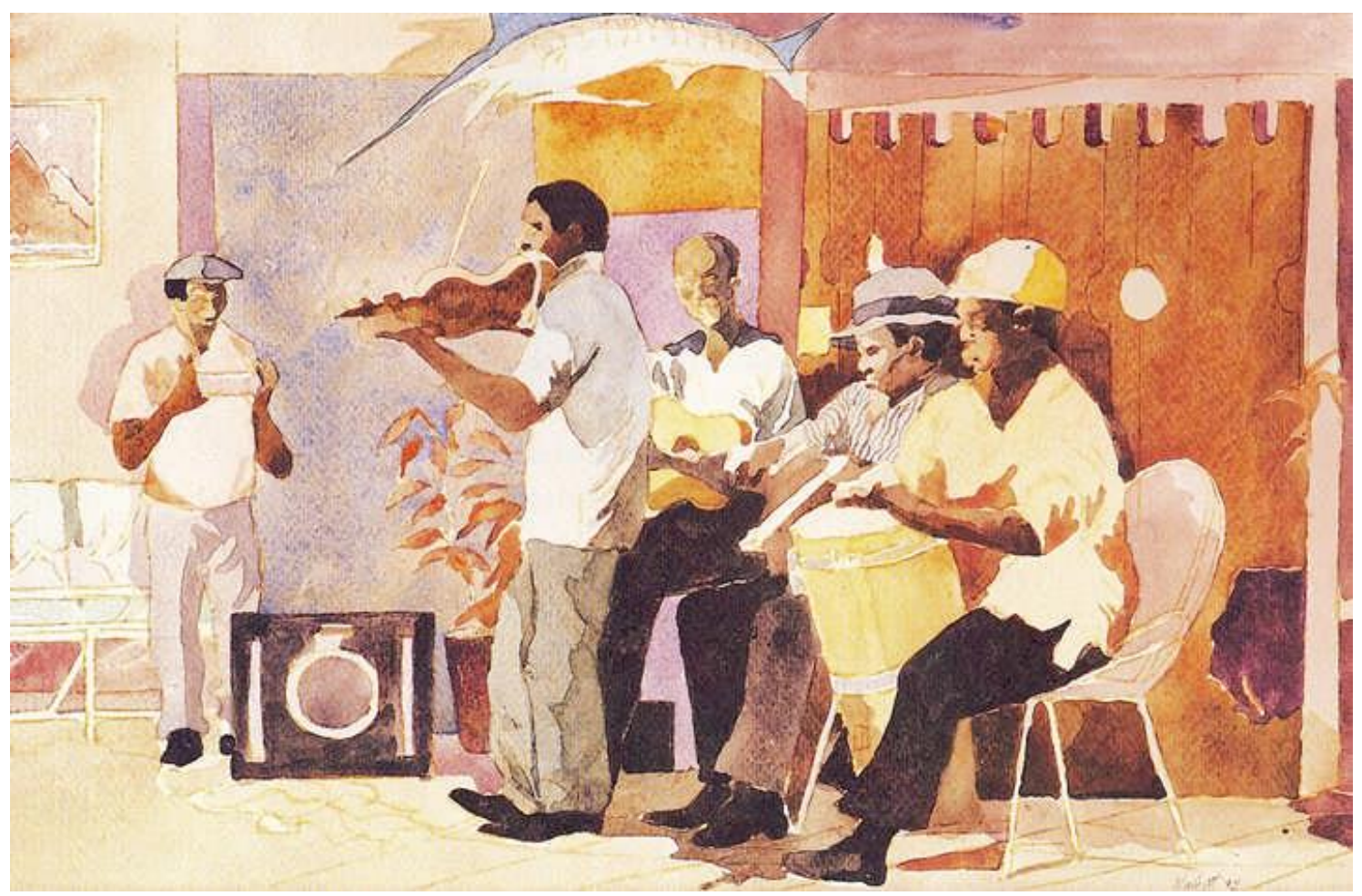

Figura 4 - Musicians, 1992, Aquarela s/ papel, 12 “x 18”.

Mignolo (2002, p. 159-160) repara nas inúmeras contribuições feitas ao estudo do imaginário por Glissant, ao chamar a atenção para a necessidade de reconhecermos as imposições do modelo colonial adaptado à modernidade, pelo qual, desde o século XVI, tudo o que temos hoje é a imposição de uma única versão ocidental da História e

\section{GANPHLAC}

Revista Eletrônica da ANPHLAC, ISSN 1679-1061, Nº. 17, p. 214-234, jul./dez. 2014.

http://revista.anphlac.org.br/ 
da Literatura com "H" e "L" maiúsculos, em detrimento das histórias e literaturas dos povos que foram alijados no processo de colonização.

O estado-nação nunca substituiu a colonialidade; ele o redefiniu em relação ao colonialismo dos séculos XVI e XVII. A descolonização nunca foi realmente realizada, alcançada, nem na primeira ou na segunda fase e poderia ter sido concebida como um proceso no qual importantes degraus teriam sido vencidos, mas restou como um projeto mais do que uma realização. Situação similar poder ser verificada em relação à emancipação das colônias como um projeto dentro da modernidade, mais do que um projeto terminado.

Consequentemente, "a descolonização nunca foi realmente realizada", o modelo colonial foi embutido na construção dos estados-nação, como o foi atualmente, na globalização e na fragilização dos estados, pelas forças das corporações transnacionais financeiras. O mesmo modelo cultural está tão vivo hoje na cultura, como estava no século XVI, ou mesmo no século XIX. “A diferença é que a crítica a seus limites está surgindo não só de dentro da modernidade, mas também, e talvez principalmente, da exterioridade do mundo moderno/colonial" (MIGNOLO, 2002, p. 159-160). ${ }^{15}$

No caso da língua e das culturas, o que houve desde o século XVIII foi uma cumplicidade entre a "missão civilizadora" articulada no discurso colonial e os "processos civilizadores" que promoveram as línguas hegemônicas alemão, inglês e francês. As "outras literaturas" subalternas foram consideradas parte integrante da civilização, mas não dos estudos literários.

Dessa forma, a América Latina tornou-se, no século XIX, extensão e substituto da Europa e passou a oferecer particular interesse para a compreensão da questão das línguas, literaturas e estudos literários, na variável de distribuição do trabalho científico e das práticas culturais a partir de 1850 .

\footnotetext{
${ }^{15} \mathrm{O}$ esforço em imaginar possibilidades futuras para as margens foi pensado no século $\mathrm{XX}$, particularmente durante os anos da Guerra Fria, nos escritos de Franz Fanon, Aimé Césaire e Amilcar Cabral, entre outros. Assim como projetos repensando as margens e os centros têm crescido no Caribe, Asia, África, América Latina e sul da Europa... [...] Críticas da modernidade de dentro-exemplos do marxismo e pós-modernismo, foram necessários, mas não suficientes. O sistema colonial, incluindo o epistêmico, não desapareceu com a primeira onda de descolonização (nos Estados Unidos, Haiti e América Latina) ou da segunda (Índia, Norte da África, Indochina e regiões subsaarianas), mas persiste na força e na forma de colonialismo interno. "Assim é preciso considerar que o modelo nacional em particular, é uma versão particular histórica do modelo colonial” (MIGNOLO, 2002, p. 159-160).
}

\section{GANPHLAC}

Revista Eletrônica da ANPHLAC, ISSN 1679-1061, No. 17, p. 214-234, jul./dez. 2014. http://revista.anphlac.org.br/ 
E, em resumo as línguas e os estudos literários mantiveram-se dentro da moldura epistemológica da prática cultural e da academia da modernidade no Atlântico Norte e da configuração cultural moldada pela idéia da civilização e da missão civilizadora, juntamente com o processo de globalização econômica (MIGNOLO, 2003, p. 410-416).

A partir do século XX, os escritores migrantes tentam modificar essa situação da supremacia das três línguas, desde Aimé Césaire, que renunciou à sociedade literária parisiense para poder escrever o seu martinicano Cahier d'un retour au pays natal (1939) e viver uma vida caribenha. Segundo Gnisci (2005, p. 13-25),

A literatura atua por nós, para oferecer-nos o sentido do mundo dos mundos em que vivemos, o Tout-Monde como diz Édouard Glissant, raivoso com a globalização. É mundial a literatura que revela o mundo em que vivemos e lhe dá sentido, frente ao não sentido que circula pelo mundo. ${ }^{16}$

A importância das obras ficcionais e ensaísticas desses dois autores para a ampliação da narrativa histórica do Caribe foi evidenciada também em 2004 nas conclusões de historiadores, que levantaram 200 anos de pesquisas sobre o Caribe, verificando ser a maioria delas restritas a enfoques imperiais e políticos. ${ }^{17}$ A primeira delas é de que

tanto da perspectiva do escravo, durante o período da escravidão, quanto da maioria dos estudantes que examinaram a volumosa documentação do passado, a escravidão no Caribe não foi um sistema que desumanizou totalmente seus participantes.

E a segunda é a de que

a escravidão jamais foi um sistema estático. Apesar de tudo, a reprodução dessa estrutura coercitiva e totalizante cedeu lugar à abertura de governos democráticos na maioria dos territórios, além de

\footnotetext{
${ }^{16}$ De acordo com FONT, Joan Nogué e RUFÍ, Joan Vicente. Geopolítica, identidad y globalización. Barcelona: Ariel Geografia, 2001, p. 114, "a geopolítica contemporânea se caracteriza por uma caótica coexistência de espaços absolutamente controlados e de territórios planificados, ao lado de novas terras incógnitas que funcionam com uma lógica interna própria, à margem do sistema ao qual, teóricamente pertencem. [...] O estado-nação segue sendo uma peça fundamental na nova ordem internacional, porém, nunca como agora havia mostrado tantos signos de desorientação, desorganização e crise de suas funções tradicionais."

${ }^{17}$ Workshop realizado pela Universidade de York, EUA, que resultou em um livro em 2006.
}

\section{GANPHLAC}

Revista Eletrônica da ANPHLAC, ISSN 1679-1061, No. 17, p. 214-234, jul./dez. 2014. http://revista.anphlac.org.br/ 
evidenciar a criatividade dos próprios escravos (KNIGHT, 2006, p. 79). ${ }^{18}$

Considerações indubitavelmente surpreendentes, segundo esses historiadores, demonstrando ser a década de 1970 a infância dos estudos caribenhos, bem como o início da descoberta da literatura como fonte para novas perspectivas da narrativa histórica dos séculos XX e XXI.

\section{Fontes visuais e referências bibliográficas}

\section{Fontes visuais}

WALCOTT, Derek. Tiepolo's hound. New York: Farrar, Straus and Giroux, 2000.

Figura 1: Helen Ideal Head: Helen/Omeros, 1998, Guache e aquarela.

Figura 2: St Lucian Fishermen, 1991/ Aquarela, 7 "x 1/4".

Figura 3: Seascapes with Figures, 2002/Oleo sobre madeira, 20 "x 24.

Figura 4: Musicians, 1992/ Aquarela s/ papel, 12 "x 18”.

\section{Referências bibliográficas}

BAUGH, Edward. A history of poetry. In: A history of literature in the Caribbean. Amsterdam/Philadelphia: John Benjamins Publishing Company, 2001. v. 2.

BHABHA, Homi. O local da cultura. Belo Horizonte: UFMG, 1998.

CAMPOS, Haroldo de. Barroco, neobarroco, transbarroco. Revista Zunái de Poesia e Debates. Disponível em: http:/www.revistazunai.com/ensaios/haroldo_de_campos_transbarroco.htm.

CHEVRIER, Jacques (Org.). Poétiques d'Edouard Glissant. Paris: Sorbonne, 1999.

GLISSANT, Édouard. Introducción a una poética de lo diverso. Barcelona: Planeta, 2002. Poétique de la relation. Paris: Gallimard, 1990.

\footnotetext{
${ }^{18}$ Segundo Franklin Knight, "embora tenha deformado algumas mentes (psychés), igualar a escravidão à morte social é um vastíssimo engano. Se alguém duvida, basta recordar a história do Haiti. A escravidão mudou conforme o tempo, variando entre a zona rural e os centros urbanos. E essa variação acontecia tanto em relação às posições de gênero quanto à economía das empresas. As sociedades do Caribe eram tão criativas quanto sua produção, e uma considerável soma dessa criatividade veio dos próprios escravos" (KNIGHT, 2006, p. 7-9).
}

\section{GANPHLAC}

Revista Eletrônica da ANPHLAC, ISSN 1679-1061, No. 17, p. 214-234, jul./dez. 2014. http://revista.anphlac.org.br/ 
GNISCI, Armando. Migração e literatura. Rio de Janeiro: Unigranrio, 2004. Disponível em: http://www.unigranrio.br

O sentido do mundo na literatura. Grial, Revista Galega de Cultura. Vigo, Espanha, n. 167, p. 26- 31, julho a setembro de 2005.

HIRSCH, Edward. Derek Walcott. Fractal, v. III, n. 10, año 3, p. 63-74, julioseptiembre, 1998. Disponível em: http://www.fractal.com.mx/f10hirsc.html .

JOUBERT, Jean Louis. Édouard Glissant. Paris: adpf-Association pour la diffusion de la pensée- Ministère des Affairs Étrangèrs, 2005.

KNIGHT, Franklin. Preface. In: DE BARROS, J. et al. (Org.). Beyond fragmentation perspectives on Caribbean history. Princeton: Markus Wiener, 2006.

MIGNOLO, Walter. Rethinking the colonial model. In: HUTCHEON, Linda; VALDÉS, Mário J. (Org.). Rethinking literary history: a dialogue on theory. Oxford: Oxford University Press, 2002.

Histórias locais/projetos globais - Colonialidade, saberes subalternos e pensamento liminar. Belo Horizonte: Editora UFMG, 2003.

PHAF-RHEINBERGER, Ineke (Ed). El lenguaje-nación y la poética del acriollamiento. Una conversación entre Kamau Brathwaite y Édouard Glissant. Traducción y notas de Carolina Benavente Morales. Literatura y Linguística, Santiago, n. 19, p. 311-329, 2008. Disponível em: www.scielo.cl/scielo.php?pid=S0716...script-sci

RUSHDIE, Salman. The empire strikes back. The Times Literary Supplement, 1992.

Penguin, 1991. Imaginary homelands: essays and criticism 1981-1991. New York:

VIZIOLI, Paulo. Prefácio e tradução. In: WALCOTT, Derek. Omeros. São Paulo: Companhia das Letras, 1994.

WALCOTT, Derek. Omeros. São Paulo: Companhia das Letras, 1994.

\section{CANPHLAC}

Revista Eletrônica da ANPHLAC, ISSN 1679-1061, Nº. 17, p. 214-234, jul./dez. 2014. http://revista.anphlac.org.br/ 